\title{
Optimization of machining processes prepara- tion with usage of Strategy Manager
}

\author{
Tomáš Dodok ${ }^{1 *}$, Nadežda Čuboňová1, Dorota Wiecek $^{2}$ \\ ${ }^{1}$ University of Žilina, Faculty of Mechanical Engineering, Department of Automation and Production \\ systems, Univerzitná 1, 01026 Žilina, Slovak Republic \\ ${ }^{2}$ University of Bielsko-Biala, Faculty of Mechanical Engineering and Computer Science, Department \\ of Industrial Engineering, Willowa 2, 43-309 Bielsko-Biala, Poland
}

\begin{abstract}
At present, the optimization has an important role in machining processes preparation of $\mathrm{NC}$ programs. The article deals with the possibilities of automate creation of $\mathrm{NC}$ programs by using the $\mathrm{NC}$ strategies in CAD/CAM system Edgecam 2017 R2. The main emphasis is placed on the suitability of use, the limitation of the creation and application of the NC strategies. The experiments deal with the comparison of effectiveness of the NC strategies applied to the components with different geometric features. The experimental components are divided into two groups. First group is represented by components with 2D features. Second group is based on components with $3 \mathrm{D}$ features. The motivation for this type of research is to increasing efficiency of the machining processes creation by automation tools in $\mathrm{CAD} / \mathrm{CAM}$ systems.
\end{abstract}

Keywords: Strategy Manager, Optimization, Edgecam 2017, NC strategies.

\section{Introduction}

$\mathrm{CAD} / \mathrm{CAM}$ systems allow to shorten time of machining preparation including technological documentation,testing and manufacturing optimalization on the CNC machine. The main advantages of deploying $\mathrm{CAD} / \mathrm{CAM}$ systems include the ability to create $\mathrm{NC}$ programs for the machining of complex components that include simple featres as well as components that contain complex features or surfaces.

The necessary condition for increasing efficiency is to optimize the machining process. Optimization is a complicated multi-stage process that uses multiple methods [1-2]. From the point of view of the machining process, it is possible to optimize the choice of workpiece, machines, tools, operations, technological conditions, tool paths and so on [3-4].

In addition to optimizing the machninig process, there are also possibilyties to optimize processes within pre-production stages. One of these options is to optimize the NC program creation process so that repetetive tasks performed by the programmer can be removed when new machining processes are made. Therefore, some CAD/CAM systems, such as PLX system NX 10, CAD/CAM system Edgecam 2016 and Mastercam 2017, make it possible to create NC strategies that can be used to optimize the preparation of NC programs.

\footnotetext{
* Corresponding author: tomas.dodok@fstroj.uniza.sk

Reviewers: Stanisla Legutko, Peter Pokorný
} 


\section{The NC strategies}

$\mathrm{NC}$ strategy is defined as algorithm with conditions that define features on which the NC strategy will be used. The NC strategy contains also machining cycles [5-6]. Those machining cycles can be used for roughing and finishing operations face milling, thread making and so on. The NC strategy also contains conditions for choice of tool base e.g. for machining holes [7-8]. The NC strategies can be divided into three groups, based on the way how they are used:

a) Manual NC strategy - The NC strategy is applied manually (it does not have the necessary conditions for its automatic application). For the proper functioning of the $\mathrm{NC}$ strategy, input parameters are required from the user.

b) Semiautomatic NC strategy - The NC strategy is applied automatically to the feature for which it was determined, but requires input data from user.

c) Automatic NC strategy - the NC strategy works independently, based on entry conditions. It does not require user input and can be applied automatically to the required features.

The process of creation of NC strategies consist of several steps in Strategy Manager (Figure 1):

\section{Step}

- type and purpose of the NC strategy

2. Step
- the basic type of feature for NC strategies
3. Step
- selecting or creating the required machining cycles
4. Step
- design of the basic sequence and algorithm of the NC strategy

\begin{tabular}{l} 
5. Step \\
- proposal of basic conditions for NC strategy \\
$\begin{array}{l}\text { 6. Step } \\
\text { verification of the functionality and complete the required information } \\
\text { into NC strategy }\end{array}$ \\
\hline
\end{tabular}

\begin{tabular}{l} 
7. Step \\
- implementation of additional conditions, parameters and machining \\
cycles \\
\hline 8. Step \\
•verification of functionality and optimization of the NC strategy
\end{tabular}

Fig. 1. The methodology of NC strategy creation in CAD / CAM system Edgecam 2017 R2 
The first step, in process of creating the NC strategy, is to design the primary purpose of the NC strategy. The purpose of the NC strategy can be to machining a specific type of feature e.g. drilling holes. In the second step, the user determines for what type of feature the NC strategy will be designed for [9]. The user can design the NC strategy for one particular type of feature or for several different types of features. In the third step and fourth, the user must define the necessary machining cycles and create the basic algorithm of the NC strategy. The fifth step is to define the basic conditions. The first conditions will be focused on the choice of feature or group of features for which the NC strategy will be applied. In this step is also necessary to determine the conditions for selecting the appropriate type of tools, dimensions of selected tools and cutting parameters. In the sixth step, it is necessary to verify the basic functionality of algorithm and conditions. In the seventh step, additional conditions and parameters can be implemented [9]. These conditions and parameters allow specifying additional parameters e.g. other subtypes of feature [10-12]. In the last eighth phase, the user performs a check on the functionality of the NC strategy.

\section{Application}

Several types of components were selected to verify the functionality of the experimental NC strategies and their impact on the machining process creation (Figure 2, Figure 4 and Figure 6). Two parameters were selected to compare the effectiveness of the NC strategies. The first parameter to be compared is the time necessary to prepare machining process with and without implementation of NC strategies (Figure 3, Figure 5, Figure 7). The second parameter is machine time (Figure 8). Designed components, marked A to F (Figure 2), contain only $2 \mathrm{D}$ features. The dimensions of these componets are determined by the maximum workpiece that can be machined on the EMCO MILL 105, dimensions of workpiece are 100x50x30 $\mathrm{mm}$. For experimental components $\mathrm{K}$ to $\mathrm{N}$ (Figure 6), workpiece was designed with dimensions of $500 \times 400 \times 110 \mathrm{~mm}$. For these types of components, it is possible to use experimental NC strategies without modification.
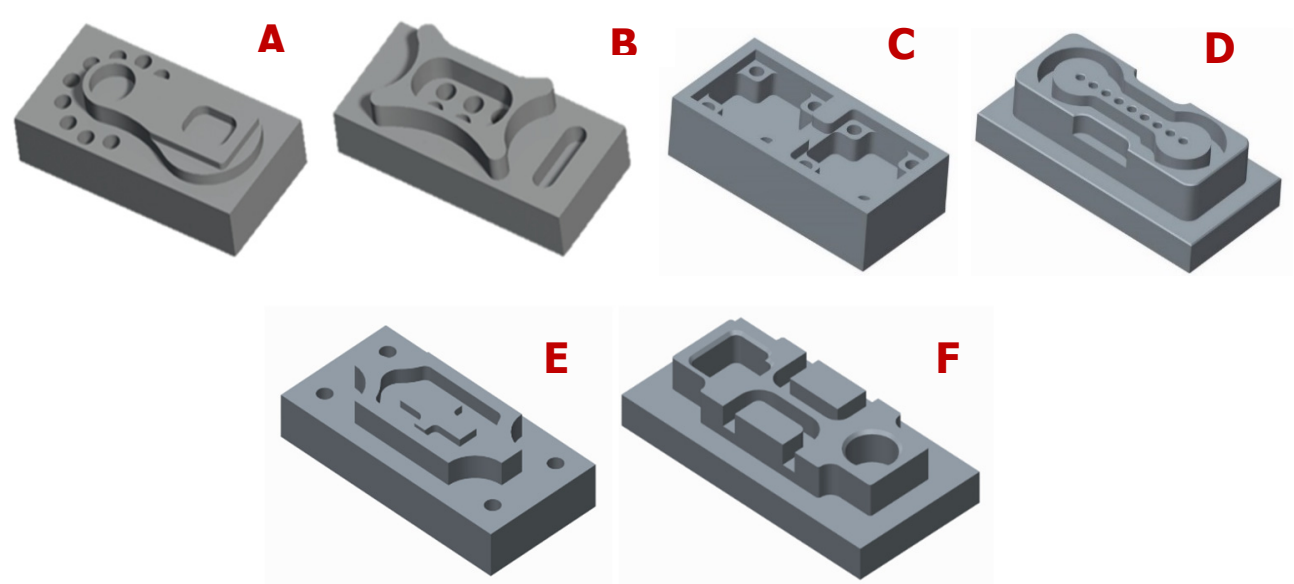

Fig. 2. First group of experimental components with $2 \mathrm{D}$ features 


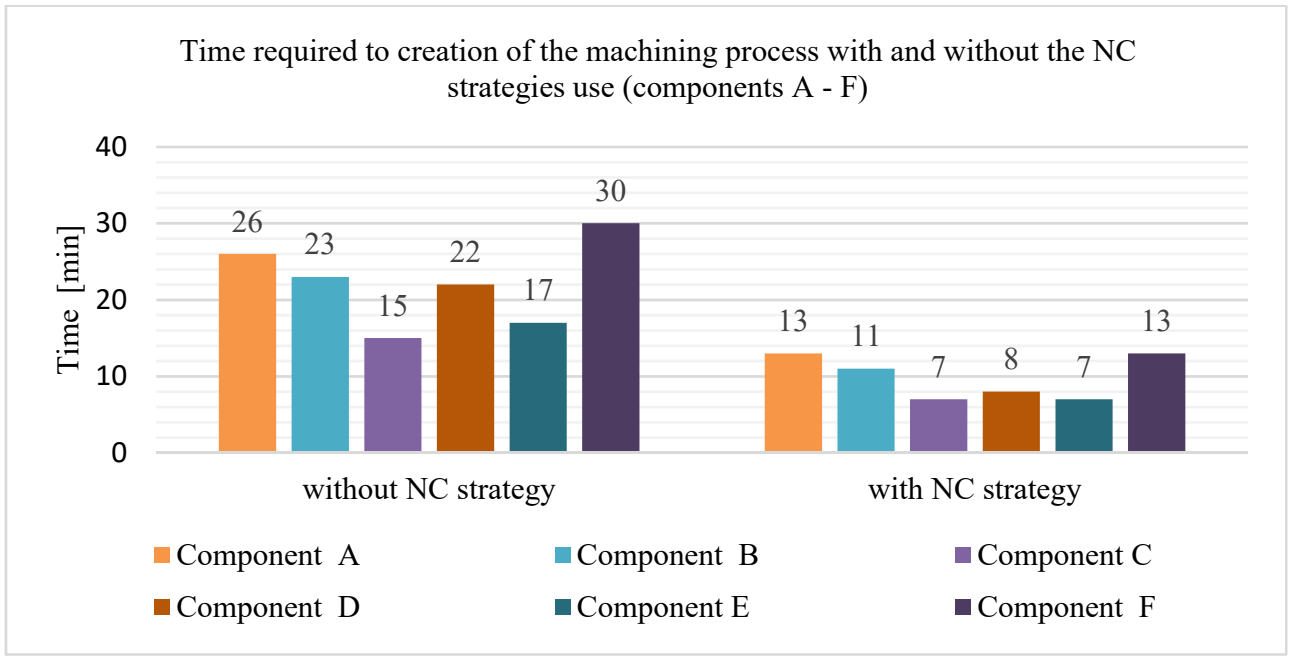

Fig. 3. Time required to create complete machining sequence with and without the NC strategies use for components A - F
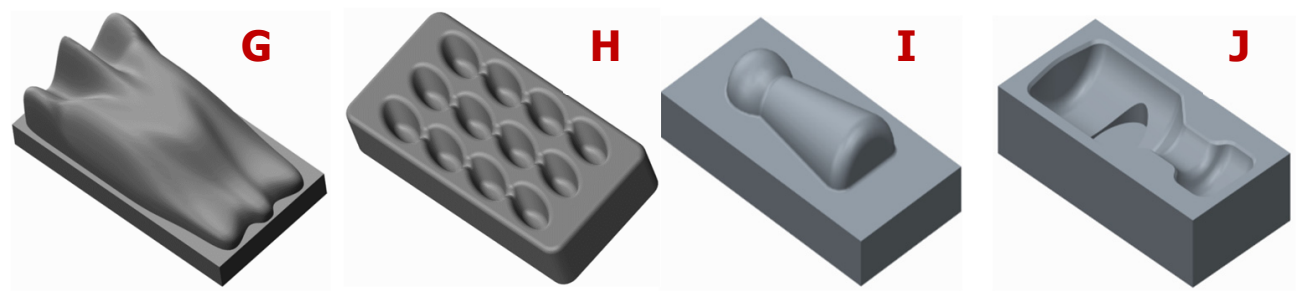

Fig. 4. Second group of experimental components with 3D features and surfaces

Time required to creation of the machining process with and without the NC strategies use (components G- J)

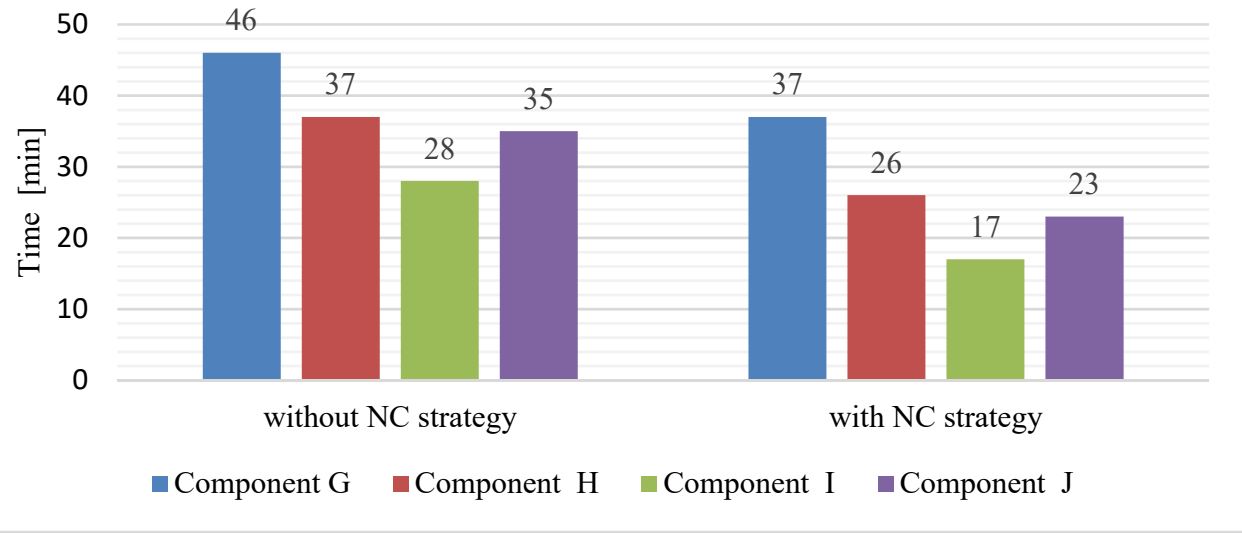

Fig. 5. Time required to create complete machining sequence with and without the NC strategies use for components $\mathrm{G}$ - J 

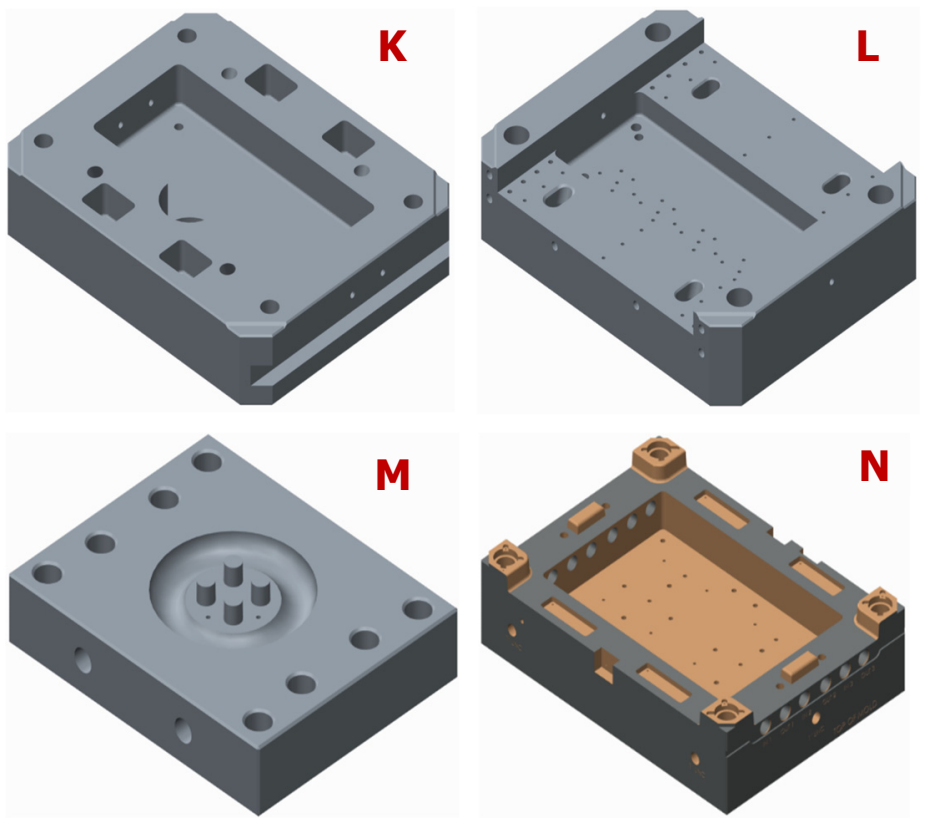

Fig. 6. Third group of experimental components with complex features

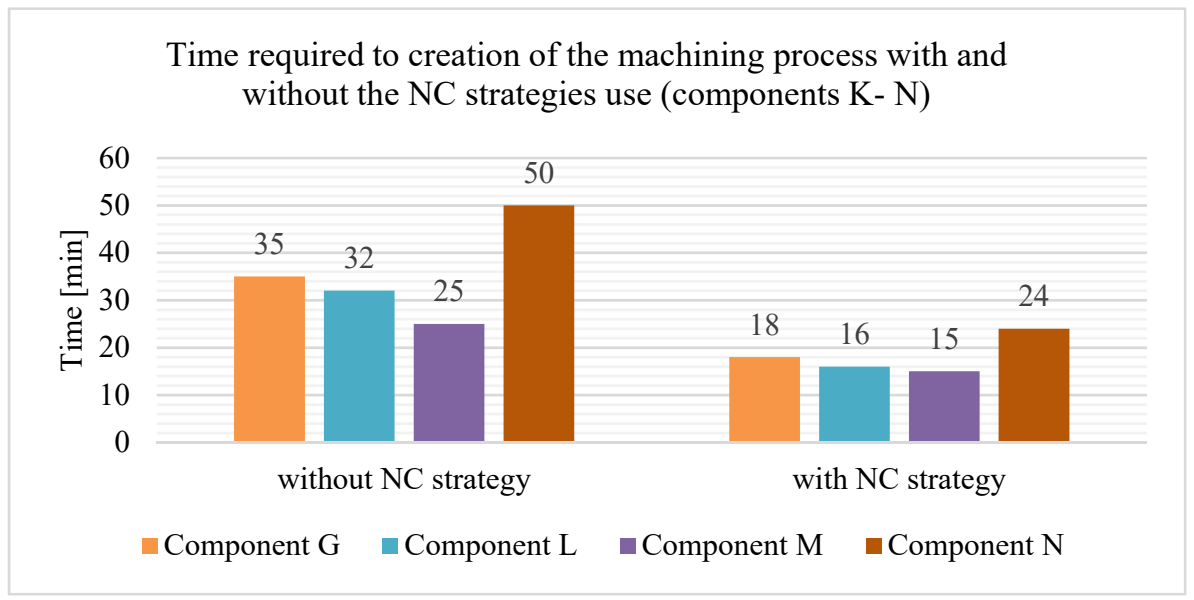

Fig. 7. Time required to create complete machining sequence with and without the NC strategies use for components $\mathrm{K}-\mathrm{N}$

The results of the experiments showed that the differences between the machining process created without the NC strategies and the machining process created by using NC strategies were minimal according to comparison of machine time generated in the CAD/CAM system Edgecam 2017 R2. 


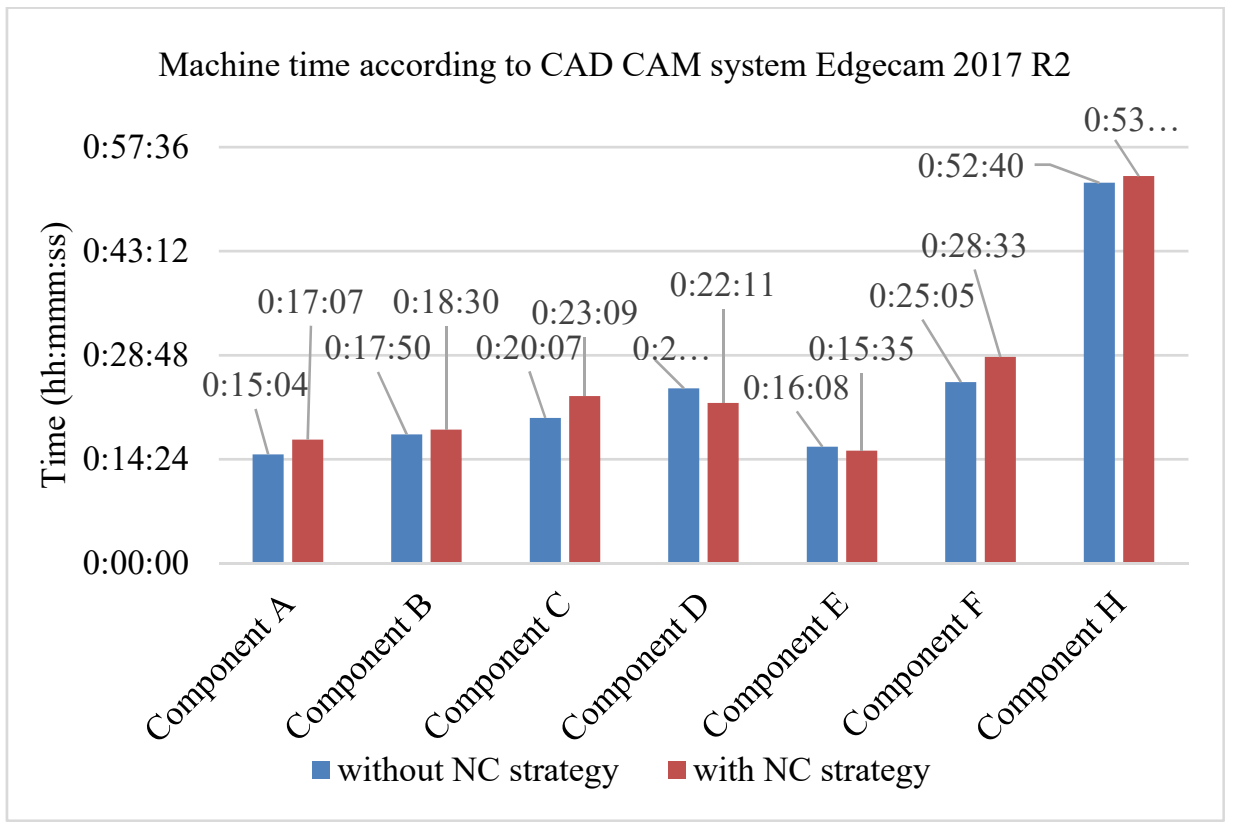

Fig. 8. Machine time according CAD/CAM system Egdecam 2017 R2

\section{Conclusion}

After getting acquainted with possibilities of preparation of the $\mathrm{NC}$ strategies in the CAD/CAM system Edgecam 2017 R2, it can be formulate the following findings:

1. The Strategy Manager constitutes a comprehensive solution for creating of NC strategies that can be used by less experienced users as well as advanced users of the CAD/CAM system Edgecam 2017 R2.

2. The process of creating an NC strategy requires basic knowledge of work with the Strategy Manager module and knowledge of the creation of the algorithms and conditions that will be used in NC strategies.

3. Before creating the NC strategy, it is necessary to perform an analysis of machined parts to determine the appropriate components or features for which the NC strategies will be created. The analysis result can be used to determine suitable technological parameters of machining cycles and conditions for NC strategies.

Base on the achieved results by the solving of this task, the following conclusion can be formulated:

a) Recognition errors of 3D features - CAD/CAM system Edgecam $2017 \mathrm{R} 2$ is not capable of correctly recognizing 3D features in certain cases. These are mainly features that are composed of several sub-features or multiple 3D surfaces. In this case, the user has several options to create the 3D feature manually. But these userdefined-features don't have same properties as automatically recognised features. What causes further problems addition problem for creation of the NC strategies and conditions. 
b) Missing shapes for slots, fillets and chamfers. The most significant problem is recognition of fillet or chamfer. CAD/CAM system Edgecam 2017 R2 recognizes these features as 2D Step or 3D Steps. The problem is caused by the absence of rules for recognition these geometric features. Same problem can be notice when recognizing 2D Slots.

c) $2 \mathrm{D}$ features. $2 \mathrm{D}$ features represent the most appropriate group for which $\mathrm{NC}$ strategies can be created. They contain enough properties to determine the conditions for choosing tools and machining cycles.

\section{References}

1. N. Čuboňová, M. Císar, Design of camera mount and its application for monitoring machining process. Advances in Science and Technology Research Journal, 9(26), 2015, 34-40.

2. B. Babic, N. Nesic, Z. Miljkovic, A review of automated feature recongnition with rulebased pattern recognition. Computers in Industry, 59(4), 321-337, 2008.

3. G. Krolczyk, S. Legutko, A. Stoic, Influence of the cutting parameters and conditions onto surface hardness of Duplex Stainless Steel. Technicky Vjesnik - Technical Gazette, 20(6), 1077-1080, 2013.

4. P. Twardowski, S. Legutko, G. M. Krolczyk, Investigation of wear and tool life of coated carbide and cubic boron nitride cutting tools in high speed milling. Advances in Mechanical Engineering, 7(6), article number: 1687814015690216, 2015.

5. V. Bulej, J. Uríček, V. Poppeová, R. Zahoranský, M. Rupiková, Study of the workspace of hybrid mechanism Trivariant. Applied Mechanics and Materials. 436 366-373, 2013.

6. T. Dodok, N. Čuboňová, I. Kuric, Workshop Programming as a Part of Technological Preparation of Production. Advances in Science and Technology Research Journal, 11(1), 2017, 111-116.

7. D. Kumicakova, A. Rengevic, M. Cisar, V. Tlach, Utilisation of kinetic sensors for the design of a human-robot collaborative workcell. Advances in Science and Technology Research Journal, 11 4), 270-278, 2017.

8. I. Kuric, V. Bulej, M. Sága, P. Pokorný, Development of simulation software for mobile robot path planning within multilayer map system based on metric and topological maps. International Journal of Advanced Robotic Systems. 10(6), pp. 14, 2017.

9. N. Náprstková, Students connecting to production problems resolutions in CAD/CAM area. $9^{\text {th }}$ International Scientific Conference - Engineering for Rural Development 2010, Jelgava, Litvia, 310-314, 2010.

10. A. Rudawska, M. Reszka, T. Warda, I. Miturska, J. Szabelski, D. Stančeková, A. Skoczylas, Milling as a method of surface treatment in adhesive bonding. Journal of Adhesion Science and Technology, 30(23), 2619-2636, 2016.

11. J. Stanček, V. Bulej, Design of driving system for scissor lifting mechanism. Academic Journal of Manufacturing Engineering. 13(4), 38-43, 2015.

12. M. Drbúl, D. Stančeková, O. Babík, J. Holubjak, I. Görögová, D. Varga, Simulation possibilities of $3 D$ measuring in progressive control of production. Manufacturing Technology, 16(1), 53-58, 2016. 